\title{
AOR
}

Selected Papers of \#AolR2021:

The 22nd Annual Conference of the

Association of Internet Researchers Virtual Event / 13-16 Oct 2021

\section{AN ONLINE WORK IS STILL A WORK: VIRTUAL LABORS OF PROFESSIONAL WRESTLERS}

\author{
CarrieLynn Reinhard \\ Dominican University \\ Jessica Fontaine \\ McGill University \\ DeWitt King \\ The University of New Mexico
}

The COVID pandemic's impact on professional wrestling has come in many forms. Like other forms of sports and entertainment, professional wrestling is very dependent on physical interactions to produce content. So, what happens when wrestlers, who work as independent contractors, cannot engage in such physical labor? Fortunately, many had already been utilizing existing social media platforms as additional sources of income to supplement what they receive from their wrestling, trading on their characters and brands under neoliberal approaches to revenue generation. Their online work often aligns with their physical work, as the actual wrestling they perform is only a small fraction of their revenue-generating labor. From selling merchandise to selling themselves, the panel explores how professional wrestling uses these technologies to further their physical businesses and practices. The panel will critically explore these online activities to understand how such technologies mediate the relationship between promotions, wrestlers, and fans while also reflecting late-stage capitalist and neoliberal ideological perspectives on the Internet. This panel considers how these independent contractors have turned to neoliberal platforms and practices, even before the pandemic, to maintain a living, and the extent to which what they have done to survive operates as a template for more people in post-industrial societies operating under similar conditions. 


\title{
FROM YOUTUBE TO TNT: PROFESSIONAL WRESTLING, TRANSMEDIA STORYTELLING, AND FAN ENGAGEMENT IN ALL ELITE WRESTLING
}

\author{
CarrieLynn Reinhard \\ Dominican University
}

On May 5, 2016, brothers Matt and Nick Jackson published "Being the Elite (Episode 1)" on YouTube at https://www.youtube.com/BeingTheElite, unaware it would change the professional wrestling industry. As the first Being The Elite (BTE) episode, with a running time of 6:07, the episode's description reads: "Episode 1. Tag along with Matt Jackson, Nick Jackson \& Kenny Omega as they make their voyage through the world of wrestling." The video, however, lacked meaning for viewers unfamiliar with these three individuals, who wanted to give their devoted fans a behind-the-scenes peek at their "real world" experiences. In the four years since, BTE has garnered over 203,000 views, 4,400 likes, and became increasing more kayfabe-based, blurring the lines between "behind-the-scenes" and fictional worldbuilding (Fiorvanti \& Wonsover 2017). What began as a means "to entertain themselves on the road" eventually grew into a wrestling company, both providing these wrestlers "an outlet [...] to express their own creativity" (Collings 2020).

BTE helped expand the wrestlers' fanbase, as new fans discovered them through YouTube and/or via their wrestling matches for New Japan Pro Wrestling (NJPW), Ring of Honor (ROH), and Pro-Wrestling Guerilla (PWG). Building this fanbase allowed the Jacksons and Omega to expand their influence in professional wrestling, launch a lucrative merchandise line with Hot Topic, and eventually prove their critics wrong by selling out the largest indie wrestling show in history, the pay-per-view (PPV) All In (Barrasso 2018). All In's success helped create All Elite Wrestling (AEW) and the development of a brand to rival the largest name in professional wrestling, World Wrestling Entertainment (WWE). Even with a successful primetime series on TNT, the Jacksons and Omega maintained their YouTube channel, and their relationship with their fans, tying the BTE stories into the AEW stories.

With approval from $\mathrm{ROH}$, the Jacksons created the BTE series to showcase their experiences on the road (Fiorvanti \& Wonsover 2017). Eventually, more wrestlers joined them, and episodes developed increasingly complex storylines, such as when Cody Rhodes became "possessed" by the WWE and required an exorcism. Overall, "the real force of [Being the Elite] has been tongue-in-cheek humor and its advancement of storylines that have taken place in different wrestling promotions across the globe" (Collings 2020). Many episodes feature intertextual references through jokes, parodies, and comments to other professional wrestling characters, storylines, events, and industries.

The channel also features other content, including the webseries Wrestlers on the Road Ordering Room Service as well as special event videos. BTE's success led to the self- 
financed All In on September 1, 2018 after journalist Dave Meltzer declared that no indie wrestling show could sell out a 10,000 seat arena (Eck); All In sold out in less than an hour (Rueter 2018). Based on the PPV's success, Omega, Rhodes, and the Jacksons announced AEW on January 1, 2019 via a BTE episode, with the first AEW PPV, Double or Nothing, happening on May 25, 2019 (Pratt 2019). Soon after, the group announced a television deal with TNT for Dynamite to air that fall (Otterson 2019). Every Dynamite episode is accompanied by AEW Dark episodes on the AEW YouTube channel. Each Dark episode involves extra matches not aired on TNT and, while pretaped, is livestreamed. Along with the YouTube channels, AEW maintains two accounts on Tik Tok, one on Instagram, and several on Twitter.

Across these platforms, BTE/AEW demonstrates intertextuality and dialogue, both of which strengthen the parasocial relationship between producers and fans. Engaging in this transmedia experience provides "for new emotional investments to grow in a story, as it offers a sense of autonomy in that the fan is discovering and creating meaning to the story on their own terms," although the structures the producers designed impact how fans interact with the property (Nguyen 2013: 56-7). Of course, while the producers create those structures, their promulgation is only possible because the fans demand the content they could supply.

Fans and producers, then, exist in a symbiotic relationship, both exploiting the other and themselves for mutual benefit. Instead of seeing such relationships as conflictual and antagonist (see Nguyen 2013), an interactionist approach would consider them as active agents in a complex network that assume different identities across time and space. All participants are subjected to factors outside their control, while exerting power over circumstances they can control. BTE/AEW must contend with the demands of businesses, governments, regulators, and even the fans to develop their content (see Reinhard 2019). For transmedia fans, this means existing in various positions within the experience and enacting different identities that appear contradictory but are experienced as normal.

Thus, this presentation considers the role of BTE in the formation of AEW as well as the promotion of various AEW wrestlers, acting as a counter-point to WWE and consisting of a bottom-up, user-generated, DIY ethics and aesthetics. The paper presents how BTE/AEW started this way and how it became this source of promotion or "getting over" during the COVID pandemic for wrestlers like the Dark Order, the Varsity Blondes, Fuego del Sol, and more.

BTE/AEW gave wrestlers increased self-determination while giving fans content more aligned with their desires. This symbiotic relationship between producers and fans, passive and active audiences, helps all achieve their goals. Therefore, being a transmedia fan fundamentally aligns with being a fan. Fans often engage with paratexts or ancillary goods in relation to the original or canonic text. To be a fan is to be exploited "to obtain the emotions that drive their connection to a story" (Nguyen 2013: 67). Transmedia fandom involves interaction, engagement, and power, all of which flows between agents in the network that depend on each other for success, just as the 
content on different platforms depend on each other for the transmedia experience to succeed. Since fans and producers rely on each other, engagement becomes more important than just audience size. Engagement becomes capital, both economic and sociocultural, as the resource that producers and fans use to justify their work. To encourage this engagement, more dialogue and interaction occurs in transmedia fandom. BTE/AEW would not be successful, let alone even exist, without such engagement with their fans.

\section{References}

Barrasso, B. (2018). "How The Young Bucks Transformed Themselves into Wrestling's Best Storytellers." Sports Illustrated, https://www.si.com/wrestling/2018/03/02/youngbucks-wrestling-top-storytellers.

Collings, J. (2020). "View from the Turnbuckle: The 10 Greatest Moments in Being the Elite History." Wrestling Inc, https://www.wrestlinginc.com/news/2020/04/views-fromthe-turnbuckle-the-10-greatest-moments-in-being-669602.

Fiorvanti, T. \& Wonsover, M. (2017). "Blurring the Lines: How Kenny Omega and The Young Bucks Changed the Game with 'Being the Elite'." ESPN.com, http://www.espn.com/wwe/story/ /id/19590596/kenny-omega-young-bucks-changedgame-being-elite.

Nguyen, V. L. (2013). Exploit Me! Emotional Capital and Power in Transmedia Storytelling, Master's Thesis, American University of Paris.

Otterson, J. (2019). "All Elite Wrestling to Launch on TNT Wednesdays in October." Variety, https://variety.com/2019/tv/news/aew-tnt-premiere-date-1203277974.

Pratt, E. (2019). "The Young Bucks and Cody Officially Announced All Elite Wrestling and Released Some Details," Uproxx with Spandex, https://uproxx.com/prowrestling/young-bucks-cody-all-elite-wrestling-announcement$\underline{2019}$.

Reinhard, C. D. (2019). "Kayfabe as Convergence: Content Interactivity and Prosumption in the Squared Circle," In C. D. Reinhard \& C. J. Olson (eds.), Convergent Wrestling: Participatory Culture, Transmedia Storytelling, and Intertextuality in the Squared Circle. Routledge: pp. 31-44.

Rueter, S. (2018). "All In Sold Out in Under an Hour," Cageside Seats, https://www.cagesideseats.com/2018/5/13/17350226/all-in-sold-out-under-an-hourcody-rhodes-young-buck-bullet-club. 


\section{DIGITAL MERCH TABLES AND "WORKING" ONLINE: THE ALWAYS- ALREADY-ONGOING AND EXCESSIVE LABOR OF PROFESSIONAL WRESTLING}

Jessica Fontaine

McGill University

On March 17, 2021, less than an hour after her "unsanctioned lights out" main event match concluded, All Elite Wrestling (AEW) professional wrestler Britt Baker tweeted "Shopaew.com" with an image of her bloodied face and the words "Main Event Role Model" emblazoned on a new black t-shirt available for immediate purchase on AEW's online store. Baker, a "heel" or villain in wrestling storytelling practices, lost to her opponent, the babyface hero Thunder Rosa in a violent match that saw both wrestlers attack each other with a number of weapons and ended with Baker's face covered in blood. Although the match had been pre-taped the week before, professional wrestling's conventions of "liveness" (Auslander, 2008) gave the appearance that Baker, perhaps, published the tweet from backstage while receiving stitches or having the remaining tacks pulled from her back.

Over the following days, Baker liked and retweeted fans' pictures of their recently purchased t-shirts and tweets from wrestlers, journalists, and fans celebrating the match and her performance in it. Pro Wrestling Tees, the manufacturer and distributor of AEW's t-shirts, declared the "Main Event Role Model" t-shirt the week's best seller. Following Baker's mediatized work from her televised, bloody in-ring performance, her promotion of the mass commodity of the t-shirt, and her generation of "likes" and retweets, this paper seeks to attend to the interdependence of bodily and digital labor in the professional wrestling industry and more broadly.

This paper will examine how Baker, like many female wrestlers, negotiates the conjoined demands of the professional wrestling industry's affective economy and storytelling conventions, and an online "economy of visibility" (Banet-Weiser, 2018) by articulating forms of bodily and digital labor through the logics of "popular feminism", a feminist discourse that plays out across media platforms, "values neoliberal principles of individualism and entrepreneurialism", focuses on "the individual body", and "emphasize[s] individual attributes such as confidence, self-esteem, and competence" (Banet-Weiser, 2018, p.12-13).

Working across feminist studies, media studies, and professional wrestling studies, I will suggest that attending to Baker's social media reveals the ways in which many female wrestlers are engaged in a "confidence game" (Banet-Weiser, 2018) that extracts "excessive" (Chow \& Laine, 2014) and "always-already-ongoing" (Pratt, 2019) labor from their bodies both on and offline. Although professional wrestling was once staged largely around live performances, it is now a highly mediatized industry in which performances and texts play out across various media platforms, including YouTube, Twitter, and Instagram (Reinhard \& Olson, 2019). At the same time, it remains a "spectacle of excess" (Barthes, 2005) or "con(fidence) game" that relies on over-the-top 
characters or "gimmicks" and emotional storytelling for its business. Baker, as a heel, is meant to draw disdain from the audience, increasing the love and adoration for her hero opponents. Moreover, because professional wrestling matches are predetermined in advance, the aim of matches is not to win competitively. Rather, the aim is to use the embodied performance to "get over" with a crowd by eliciting an affective and monetary investment through the purchases of ticket sales and merchandise (Smith, 2014; Reinhard \& Olson, 2018; Laine, 2019). Today, many wrestlers play their gimmicks online to increase exposure and further storylines (Litherland, 2014). The affective and bodily labor requirements to perform for the professional wrestling industry also spills from ring to other media platforms.

This paper will examine Baker's social media posts following her unsanctioned lights out match to explore how Baker utilizes the "affordances" (boyd, 2010) of Twitter and Instagram. I argue that Baker performs "relational labor" - "the ongoing, interactive, material, and cognitive work of communicating with people over time to create structures that can support continued work" (Baym, 2018) - and engages in two conjoined and conflicting "self-presentation strategies" (Marwick, 2013) to increase her professional status, income, and opportunities. First, I will demonstrate how Baker performs her gimmick, an over-confident and self-declared "role model" heel, by engaging in online self-promotion. Second, I will illustrate how Baker works to establish herself as a confident, competent, and "fighting" female wrestler worthy of respect and admiration in an industry that has marginalized, oversexualized, and disregarded female performers (Wood and Litherland, 2018).

In doing so, I will pay careful attention to Baker's online circulation of the "Main Event Role Model" t-shirt and the ways that she negotiates her gimmick and the "iconography of her bleeding face" - "a visible marker of pain and [and excessive] labor" (Pratt, 2019, p.146; Chow and Laine, 2014) that is generally employed in professional wrestling to gain sympathy and respect for babyfaces, not heels. Baker must ensure that she does "turn" babyface to keep in line with AEW's current storylines. At the same time, I consider how Baker's position as a thin, white, heterosexual woman enables her to make her suffering legible and highly visible in order to recuperate it for professional prestige (Wanzo, 2009). I suggest that Baker circulates and sells her own bleeding face on the t-shirt to affirm her legitimacy as a wrestler (Pratt, 2019, p. 148) and draw attention to herself as a money-making entrepreneur in the wrestling industry. As such, she embodies a neoliberal, popular feminism that is articulated through the body and its capacity to overcome injury (Banet-Weiser, 2018). Through this analysis, I aim to explore the ways that female and marginalized wrestlers are tasked with additional digital and bodily labor away from the wrestling ring to access status, income, and opportunities.

\section{References}

Auslander, P. (2008). Liveness: Performance in a mediatized culture. Routledge. Banet-Weiser, S. (2018). Empowered: Popular feminism and popular misogyny. Duke University Press. 
Barthes, R. (2005). The World of Wrestling. In N. Sammond (Ed.), Steel chair to the head: The pleasure and pain of professional wrestling. Duke University Press.

Baym, N. K. (2018). Playing to the crowd: Musicians, audiences, and the intimate work of connection. NYU Press.

boyd, danah. (2010). Social Networks Sites as Networked Publics: Affordances, Dynamics, and Implications. In Z. Papacharissi (Ed.). A networked self: Identity, community, and culture on social network sites. (pp. 39-58). Routledge.

Chow, B., \& Laine, E. (2014). Audience Affirmation and the Labour of Professional Wrestling. Performance Research, 19 (2), 44-53.

Laine, E. (2019). Professional Wrestling and the Commercial Stage. Routledge.

Litherland, B. (2014). Breaking kayfabe is easy, cheap and never entertaining: Twitter rivalries in professional wrestling. Celebrity Studies, 5(4), 531-533.

Marwick, A. E. (2013). Status update: Celebrity, publicity, and branding in the social media age. Yale University Press.

Pratt, J. (2019). Delivering Rhetorical Entanglements [Doctoral]. University of Washington.

Reinhard, C. D., \& Olson, C. J. (Eds.). (2019). Introduction: Defining convergent wrestling. In Convergent wrestling: Participatory culture, transmedia storytelling, and intertextuality in the squared circle (pp. 1-14). Routledge.

Smith, R. T. (2014). Fighting for recognition: Identity, masculinity and the act of violence in professional wrestling. Duke University Press.

Wanzo, R. (2009). The Suffering Will Not Be Televised. African American Women and Sentimental Political Storytelling. NYU Press.

Wood, R., \& Litherland, B. (2018). Critical feminist hope: The encounter of neoliberalism and popular feminism in WWE 24: Women's Evolution. Feminist Media Studies, 18(5), 905-922.

\section{FROM PRO WRESTLING FANS TO ONLY FANS: THE PRECARIOUS PRECARITY OF THE INDEPENDENT WRESTLING SCENE}

Dewitt King

University of Minnesota Twin Cities 
On April 15, 2020, World Wrestling Entertainment (WWE) posted on their website that they had come to terms on the release of 19 employees that included wrestlers, referees, and announcers. It later came out that in addition to these releases the WWE was furloughing (for an unspecified time) behind the scenes personnel and releasing talent from their development territory NXT. These announcements sent shockwaves through the pro wrestling industry because unlike many sport organizations, the WWE were still producing televised shows in the US and they were fiscally insulated due to their infamous television deal with the Kingdom of Saudi Arabia that is worth an estimated 2 billion dollars. WWE's response to the crisis of COVID-19 illuminates the precarious precarity of the pro wrestling industry. While some of the released pro wrestlers were immediately signed by WWE's competitors such as All Elite Wrestling and TNA, other wrestlers found themselves having to return to the independent wrestling scene which was also in dire straits due to Covid- 19.

Among those WWE wrestlers who were released and who did not transition into a major company was Lionel Green. Lionel Green went by the name Lio Rush during his time in the WWE and was heavily featured on Raw, 205 Live, and NXT. Despite being extremely talented in the ring and charismatic on the microphone, Green's time in the WWE was contentious as he butted heads with many of the more senior wrestlers. The root of this conflict was the fact that Green was a young and unapologetically Black man who did not respect the traditional power structure of the locker room. Upon returning to the independent wrestling scene, Green immediately established himself as a top tier talent as he wrestled a number of high profile matches. Furthermore, he tapped into his creative side when began his pursuit of music with the release of a rap album in May of 2020. And finally, most shockingly to some, and perhaps not shockingly to others, Green started an Only fans account. This paper will examine labor precarity in pro wrestling at the intersection of Blackness, masculinity, and sexuality to trace the ways Lionel Green negotiates his precarity through the commodification of his sexuality to generate income in an industry that is always already precarious through an analysis of his strategic engagement with Only fans.

This paper puts critical sport studies, Black cultural studies, critical human geography, and media studies in conversation to wrestle with the ways that the subjectivity of the independent wrestler is framed through its relationship to precarious labor. First, this paper considers and challenges our understanding of what a gig economy is (Graham et al., 2017) and how it functions in relationship to other precarious industries(Healy et al., 2017 ) closely thinking about the ways other precarious industries are able to fold into and work alongside these presumably new and unique labor conditions(Doorn, 2017; Ryan,2019). Then this paper considers the contours and granulators of Black masculinity, sexuality, and its relationship to racial capitalism (Abdel-shehid, 2005; Alexander, 2006;Malton, 2016; Oates,2007). This is animated by the question of how does the intersection of race, gender, and sexuality shift, distort, and transform the way extraction, expropriation, and dispossession occur when we think of the capaciousness nature of Blackness (Collins,2006; Ferguson, 2013).And finally, this paper wants to think critically about the ways technology can be both liberatory and disempowering to Black independent wrestlers( Benjamin,2019;Browne,2015; Chun,2009). 
Methodologically, this paper historizes and contextualizes the common independent wrestling practices of custom matches through use of a critical fabulation. Saidiya Hartman explains that "By advancing a series of speculative arguments and exploiting the capacities of the subjunctive (a grammatical mood that expresses doubts, wishes, and possibilities), I intended both to tell an impossible story and to amplify the impossibility of its telling (Hartman, 2008, p.11). This fabulation will be constructed through digital means through discursive analysis of tweets, message board comments and an analysis of the custom website themselves along with a review and analysis of Green's Only fan page. This allows for the creation of a genealogy that links the old practice of custom matches to the new practice of independent wrestlers creating Only fans accounts. Doing so allows me to argue that the deregulated nature of the pro wrestling industry is built and sustained through a genealogy of precarity which aligns with other labor constituency such as sex workers, barbers, hair stylist, uber drivers, and personal trainers.

\section{References}

Abdel-Shehid, G. (2005). Who Da Man?: Black Masculinities and Sporting Cultures. Canadian Scholars' Press.

Alexander, B. K. (2006). Performing Black masculinity: Race, culture, and queer identity. In Crossroads in qualitative inquiry.

Benjamin, R. (2019). Race After Technology: Abolitionist Tools for the New Jim Code (1st edition). Polity.

Browne, S. (2015). Dark Matters: On the Surveillance of Blackness. Duke University Press.

Chow, B. D. V. (2014). Work and Shoot: Professional Wrestling and Embodied Politics. TDR/The Drama Review, 58(2 (222)), 72-86.

Chun, W. H. K. (2009). Race and/as technology. Camera Obscura.

Collins, P. H. (2006). New commodities, new consumers: Selling blackness in a global marketplace. Ethnicities, 6(3), 297-317.

Doorn, N. van. (2017). Platform labor: On the gendered and racialized exploitation of low-income service work in the 'on-demand' economy. Information, Communication \& Society, 20(6), 898-914.

Ferguson, R. (2013). Aberrations in Black: Toward a Queer of Color Critique (First edition edition). Univ Of Minnesota Press. 
Graham, M., Hjorth, I., \& Lehdonvirta, V. (2017). Digital labour and development: Impacts of global digital labour platforms and the gig economy on worker livelihoods. Transfer: European Review of Labour and Research, 23(2), 135-162.

Hartman, S. (2008). Venus in Two Acts. Small Axe, 12(2), 1-14.

Healy, J., Nicholson, D., \& Pekarek, A. (2017). Should we take the gig economy seriously? Labour \& Industry: A Journal of the Social and Economic Relations of Work, 27(3), 232-248.

Jackson, R. (2006). Scripting the Black Masculine Body: Identity, Discourse, and Racial Politics in Popular Media (Annotated edition). SUNY Press.

Jeffries, D. (2019). \#Wwe: Professional Wrestling in the Digital Age. Indiana University Press.

Matlon, J. (2016). Racial Capitalism and the Crisis of Black Masculinity. American Sociological Review, 81(5), 1014-1038.

Miller-Young, M. (2014). A Taste for Brown Sugar Black Women in Pornography. Duke University Press.

Oates, T. P. (2007). The Erotic Gaze in the NFL Draft. Communication and Critical/Cultural Studies, 4(1), 74-90.

Ryan, P. (2019). Male Sex Work in the Digital Age: Curated Lives (1st ed. 2019 edition). Palgrave Macmillan.

Sammond, N. (2005). Steel Chair to the Head: The Pleasure and Pain of Professional Wrestling. Duke University Press.

Smith, R. T. (2014). Fighting for Recognition: Identity, Masculinity, and the Act of Violence in Professional Wrestling. Duke University Press.

Warner, K. J. (2017). In the Time of Plastic Representation. Film Quarterly, 71(2), 3237. 